\section{Football is medicine: it is time for patients to play!}

\author{
Peter Krustrup, ${ }^{1,2,3}$ Birgitte R Krustrup ${ }^{4,5}$
}

In 2006, the recognised Nordic exercise physiologists Professors Pedersen and Saltin provided powerful evidence that exercise was an effective therapy in chronic disease-they emphasised exercise as a cornerstone in the prevention and non-pharmacological treatment of lifestyle diseases. ${ }^{1}$ Shortly after, American College of Sports Medicine (ACSM)'s president Dr Sallis delivered his well-documented and strong statement that "exercise is medicine and physicians need to prescribe it!'. 2 These statements, and the research on which they are based, have influenced health authorities and governments around the globe to include exercise recommendations in the prevention and treatment of chronic diseases. Prominent worldwide exercise guidelines, including those from the WHO and ACSM, encourage sedentary individuals and patients to engage in exercise activities like brisk walking, jogging, cycling and fitness centre training. However, within physical activity guidelines, less emphasis has been placed on the health benefits of sporting activities.

\section{IS THERE EVIDENCE THAT SPORT PROVIDES HEALTH BENEFITS?}

In a 2012 Lancet review, it was concluded that 'sport may contribute to the health of nations'. ${ }^{3}$ A subsequent meta-analysis

1 Department of Sports Science and Clinical Biomechanics, SDU Sport and Health Sciences Cluster (SHSC), Faculty of Health Sciences, University of Southern Denmark, Odense, Denmark

${ }^{2}$ Sport and Health Sciences, College of Life and Environmental Sciences, University of Exeter, Exeter, UK ${ }^{3}$ Department of Sports Science, Shanghai University of Sport, Shanghai, China

${ }^{4}$ DBU Zealand, Roskilde, Denmark

${ }^{5}$ Department of Nutrition, Exercise and Sports (NEXS), University of Copenhagen, Copenhagen, Denmark

Correspondence to Professor Peter Krustrup, Department of Sports Science and Clinical Biomechanics, Faculty of Health Sciences, University of Southern Denmark, Odense 5230, Denmark; pkrustrup@health.sdu.dk high-intensity interval training. published in 2015 concluded that, in terms of health effects of sport, 'the best evidence was found for football and running', and that 'evidence for health benefits of other sport disciplines was either inconclusive or tenuous'. Since then, high-quality research has emphasised the preventive effects of several ball games for sedentary adults, and we report that the evidence for the health benefits of football (soccer) is even stronger. ${ }^{5-10}$ More than 150 peer-reviewed articles published in 35 international scientific journals tell us that football is a joyful, social and popular sporting activity that is effective and versatile; a multipurpose type of training with marked positive effects for almost all types of people and across their lifespan. ${ }^{5-10}$ The most popular sport in the world is much more than entertainment: football is broad-spectrum

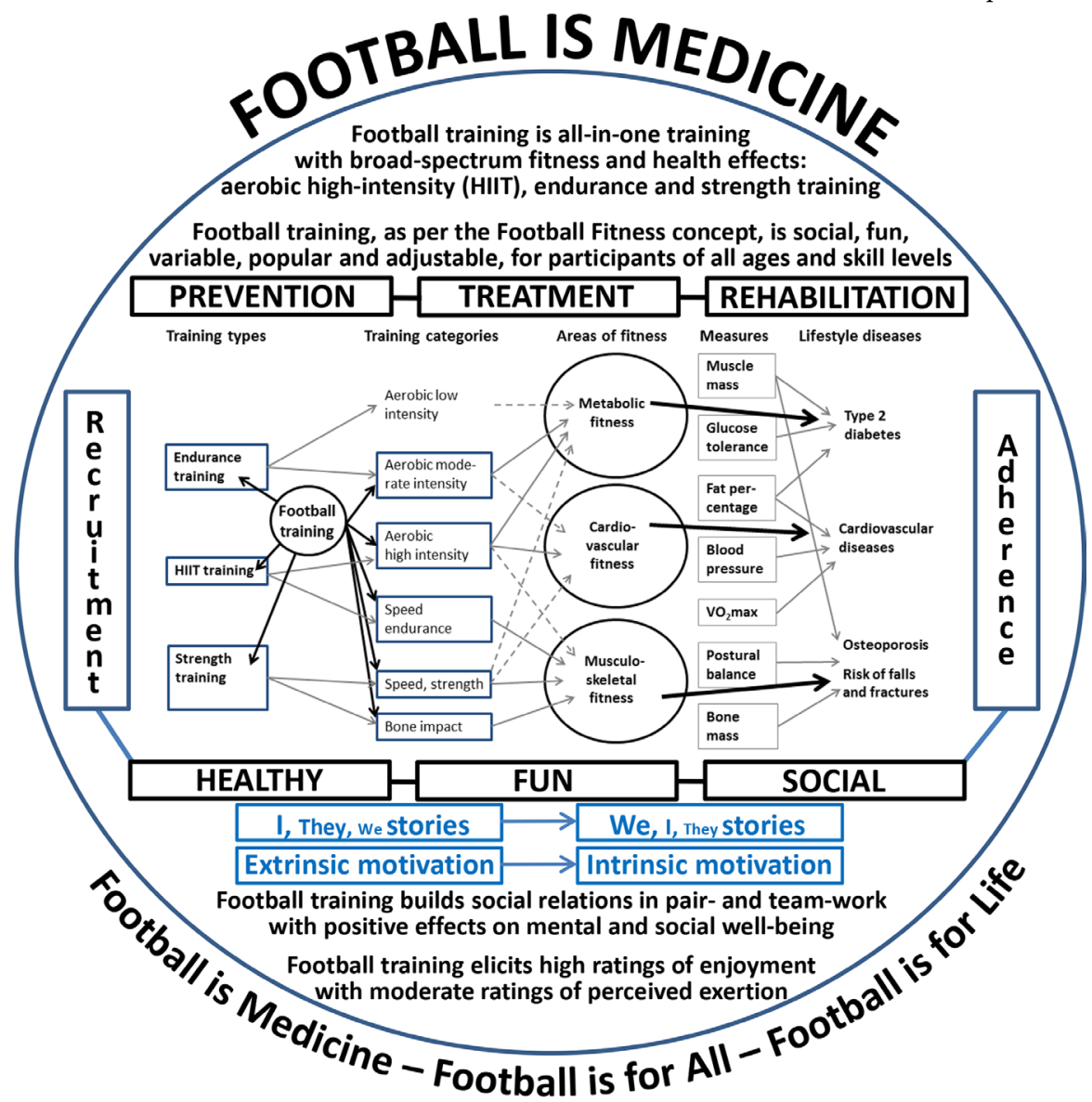

Krustrup and Krustrup, 2018

Figure 1 A holistic 'Football is Medicine' model, describing the training components of football training; the training-induced adaptations in fitness and health variables; the link between the training stimuli to cardiovascular, metabolic and musculoskeletal fitness; and the use of football training in the prevention, treatment and rehabilitation of non-communicable diseases, as well as the psychosocial elements of acute football training, organised as per the Football Fitness concept, and the long-term psychosocial training-induced effects and the possibility of creating adherence to an active lifestyle. Modified from Krustrup et al $2010^{6}$ and Krustrup et al $2018 .^{8}$ HIIT, aerobic 
medicine against lifestyle diseases. ${ }^{7-9}$ In this editorial, we guide the reader to the crux of the evidence.

\section{THE EVIDENCE FOR FOOTBALL AS MEDICINE}

Our football for health research started in 2003 with observational pilot studies on movement patterns, exercise intensity and fitness benefits of football training. These investigations included Danish low-level senior and veteran players, homeless men and sedentary computer enthusiasts, the so-called FC Zulu team, with no prior football experience. Interesting pilot results demonstrated an average increase in $\mathrm{VO}_{2} \max$ from 35 to $52 \mathrm{~mL} / \mathrm{min} / \mathrm{kg}$ over 2 years for the FC Zulu players and led to the first RCTs in 2006-2008 on football training compared with other popular exercise regimes for sedentary young men $^{56}$ and women. ${ }^{8} 10$ From 2010 onwards, numerous randomised controlled trials were conducted for football training in patient groups with hypertension, type 2 diabetes, osteopaenia, and prostate and breast cancer (see reviews ${ }^{6}$ and meta-analyses $^{479}$ ). The past 15 years of research has led us to conclude that football training is an intense and versatile training type that combines endurance, aerobic high-intensity interval (HIIT) and strength training for participants of all ages and skill levels (figure 1). Football may therefore be characterised as an all-in-one type of training with broad-spectrum fitness effects for the general population, with football training for $2 \times 1$ hour per week resulting in marked positive and simultaneous effects on cardiovascular, metabolic and musculoskeletal fitness. ${ }^{6} 8$ Specifically meta-analyses have revealed an increase in $\mathrm{VO}_{2} \max$ of $3.5 \mathrm{~mL} / \mathrm{min} / \mathrm{kg}$ in $12-26$ weeks $^{{ }^{7}}$ as well as a $1.7 \mathrm{~kg}$ loss in fat mass and $1.1 \mathrm{~kg}$ increase in muscle mass in $12-16$ weeks $^{9}$ for sedentary adults, along with a $11 / 7 \mathrm{~mm} \mathrm{Hg}$ drop in BP in 12-16 weeks for 30-75 year-old patients with mild-to-moderate hypertension. ${ }^{9}$ This cumulative evidence establishes football as a an effective broad-spectrum prevention, treatment and rehabilitation strategy for a broad range of patient groups (figure 1).

A holistic 'Football is Medicine' model (figure 1) is highlighted for consideration. We compile the rigorous research into:

- Movement pattern and physiological response (sports physiology).
- Training-induced fitness adaptations (training physiology).

- Training-induced health-related adaptations (sports medicine).

- Motivational and psychosocial climate during training (sports psychology).

- Long-term training-induced psycho-social effects, as well as

- development and implementation of evidence-based football training concepts (sports sociology).

\section{IT IS TIME FOR PATIENTS TO PLAY!}

The use of football as a therapy has enormous global implications. First, football as medicine is cheap and easily distributed all over the world as football training is already performed by an estimated 500 million players worldwide, of which 300 million are registered in clubs. ${ }^{3}$ Second, the use of a motivating and social activity as medicine against diseases may well make it easier for patients to take the exercise pill and to adhere to lifestyle changes ${ }^{6810}$ (figure 1). Note that most of the available research relates to football training, as per the 'Football Fitness' concept, comprising 1-hour sessions with proper warm-up, pair-based football exercises and 2 vs 2 to 5 vs 5 football drills with rules adjusted to the participant group. This type of football training is organised so that it encourages life-long participation for almost everybody and results in few injuries compared with the type of match-play football seen on television. ${ }^{6810}$ Football training is social, fun, variable, adjustable and popular both in short-term and long-term programmes for participants of all ages, skill levels and socioeconomic background ${ }^{6} 810$ (figure 1). Football training elicits high ratings of enjoyment with moderate ratings of perceived exertion and it builds social relations in pair-work and teamwork with positive effects on mental and social well-being. ${ }^{6} 810$ (figure 1). Football is medicine-it is time for patients to play!

Acknowledgements The authors would like to thank the team at University of Southern Denmark, Department of Sports Science and Clinical Biomechanics, as well as more than 250 collaborators in 22 countries. A special thanks to Professor AnneMarie Elbe from University of Leipzig, Germany, Associate Professor Laila Ottesen, University of Copenhagen, Denmark, and Associate Professors Morten Bredsgaard Randers Thomsen and Magni Mohr, University of Southern Denmark, Odense, Denmark, for helpful commenting of this editorial, and to the Danish Football Association (DBU) and the Danish Sports Confederation (DIF) for continuous innovative collaboration and support.
Contributors Both authors contributed equally to the editorial work and approved the final version of the manuscript.

Funding The authors have not declared a specific grant for this research from any funding agency in the public, commercial or not-for-profit sectors.

Competing interests None declared.

Provenance and peer review Not commissioned; externally peer reviewed.

\section{(1) \\ OPEN ACCESS}

Open access This is an open access article distributed in accordance with the Creative Commons Attribution Non Commercial (CC BY-NC 4.0) license, which permits others to distribute, remix, adapt, build upon this work non-commercially, and license their derivative works on different terms, provided the original work is properly cited and the use is non-commercial. See: http:// creativecommons.org/licenses/by-nc/4.0/

(c) Article author(s) (or their employer(s) unless otherwise stated in the text of the article) 2018. All rights reserved. No commercial use is permitted unless otherwise expressly granted.

\section{D) Check for updates}

To cite Krustrup P, Krustrup BR. Br I Sports Med 2018;52:1412-1413.

Accepted 17 May 2018

Published Online First 9 June 2018

Br J Sports Med 2018;52:1412-1413.

doi:10.1136/bjsports-2018-099377

\section{REFERENCES}

1 Pedersen BK, Saltin B. Evidence for prescribing exercise as therapy in chronic disease. Scand J Med Sci Sports 2006;16(Suppl 1):3-63.

2 Sallis RE. Exercise is medicine and physicians need to prescribe it!. Br J Sports Med 2009;43:3-4.

3 Khan KM, Thompson AM, Blair SN, et al. Sport and exercise as contributors to the health of nations. Lancet 2012:380:59-64.

4 Oja P, Titze S, Kokko S, et al. Health benefits of different sport disciplines for adults: systematic review of observational and intervention studies with metaanalysis. Br I Sports Med 2015:49:434-40.

5 Krustrup P, Nielsen JJ, Krustrup BR, et al. Recreational soccer is an effective health-promoting activity for untrained men. Br J Sports Med 2009;43:825-31.

6 Krustrup P, Aagaard P, Nybo L, et al. Recreational football as a health promoting activity: a topical review. Scand I Med Sci Sports 2010;20(Suppl 1):1-13.

7 Milanović Z, Pantelić S, Čović N, et al. Is recreational soccer effective for improving VO2max a systematic review and meta-analysis. Sports Med 2015;45:1339-53.

8 Krustrup P, Helge EW, Hansen PR, et al. Effects of recreational football on women's fitness and health: adaptations and mechanisms. Eur J Appl Physiol 2018:118:11-32.

9 Milanović Z, Pantelić S, Čović N, et al. Broad-spectrum physical fitness benefits of recreational football: a systematic review and meta-analysis. Br I Sports Med 2018. doi: 10.1136/bjsports-2017-097885. [Epub ahead of print $25 \mathrm{Jan} 2018]$.

10 Ottesen L, Jeppesen RS, Krustrup BR. The development of social capital through football and running: studying an intervention program for inactive women. Scand $J$ Med Sci Sports 2010;20(Suppl 1):118-31. 